\title{
ASSESSMENT OF THE LEACHABILITY AND MECHANICAL STABILITY OF MUD FROM A ZINC-PLATING PLANT AND WASTE ZEOLITE BINDING WITH PORTLAND CEMENT
}

\author{
Damir Barbir ${ }^{1}$, Pero Dabić ${ }^{2}$, Ana Lisica ${ }^{3}$ \\ ${ }^{I}$ Department of Inorganic Technology, Faculty of Chemistry and Technology, University of Split, Croatia \\ ${ }^{2}$ Department of Inorganic Technology, Faculty of Chemistry and Technology, University of Split, Croatia \\ ${ }^{3}$ Department of Inorganic Technology, Faculty of Chemistry and Technology, University of Split, Croatia
}

\begin{abstract}
The study has examined the immobilization of mud from a zinc-plating plant and waste zeolite materials with Portland cement type CEM I. Determination of leachability was assessed by NEN 7345 leaching test. The mechanical stability of immobilized samples was tested by measuring compressive and flexural strength. The samples with the addition of mud showed high mobility of zinc ions with leachability index values below criteria limit. With the addition of waste zeolite in cement-mud system, zinc has become less mobile with greater leachability index. According to diffusion model, controlling mechanism for leaching of zinc is a wash-off (except for the sample with the addition of $5 \%$ of mud). For samples with lower addition of waste zeolite, leaching mechanism is diffusion, whereas at higher additions, the leaching mechanism is wash-off. Identification of forming hydrated products was carried out using Fourier transform infrared technique.
\end{abstract}

Keywords: Portland cement, mud from a zinc-plating plant, waste zeolite, mechanical stability, leaching of zinc

\section{INTRODUCTION}

In recent years, rapid industrialization has led to an increase in the quantity of hazardous wastes. These waste materials must be properly disposed or reused in new composite materials. This includes methods of waste treatment and stabilization/solidification $(\mathrm{S} / \mathrm{S})$ process with cementitious or pozzolanic binders $[1,2]$. S/S process reduces the hazardous potential of waste materials by transforming wastes into less soluble form and improves the handling and physical characteristics of wastes $[3,4]$. Cement-based S/S process is based on the reactions of Portland cement and constituents from the waste material (heavy metals). These interactions can be very complex and have great importance to the quality of the stabilized wastes.

In general, most of the crystalline calcium silicate from cement reacts with water to form an amorphous hydrated calcium silicate (C-S-H gel) and crystalline calcium hydroxide (Portlandite). The C-S-H gel is the main binding component of the stabilized waste while Portlandite creates an alkaline environment $(\mathrm{pH}>12)$. As a result, there is a high $\mathrm{pH}$ neutralization of acid solution in contact with stabilized waste, thus preventing the leaching of heavy metals. Also, the present hydroxide converts the waste's heavy metal ions into poorly soluble hydroxides. Portlandite is partially soluble and over an extended period under the influence of moisture diffuses through the pores and leaches from solidified waste. Because its leaching it can lead to degradation of the structure of solidified material [5].
Cement hydration can change under the influence of heavy metals during the formation of sheath around cement particles [6]. Poon et al. concluded that the metals contained in the sparingly soluble hydroxide retard hydration, while those consisting of a soluble hydroxides accelerate the hydration process $[7,8]$. Retardation is attributed to the reduction in permeability of the resulting products, which leads to deposition of undissolved metallic gel on the surface of the cement particle [9]. Hills et al. concluded that reaction rates of cement phase do not depend only on the composition and structure, but also on the temperature, size, particle shape as well as the presence of accelerators and retarders (gypsum, calcium chloride, calcium hydroxide, $\left.\mathrm{CO}_{2}\right)[10,11]$.

In an alkalline environment as present during cement hydration, the surface of cement particles are negatively charged. This surface can adsorb metal cations. Most available cations in the solution are calcium ions and it is believed that this ion-coated silicate surface creates a highly charged Ca-layer. Metal anions in the solution will compete for adsorption sites, creating an additional layer. Asavapisit et al. examined this competition for adsorption by studying the effects of synthetic lead, zinc and cadmium hydroxide on calcium ions during the hydration of ordinary Portland cement. They concluded that during the early hydration of Alite, dissolves large quantities of lead and zinc ions. They assumed that these ions prevent the formation of $\mathrm{Ca}(\mathrm{OH})_{2}$ in the first week of hydration of Alite [12]. Poon et al., through porosity and leaching experiments showed that $\mathrm{Zn}$ was retained in the cement matrix. Observed leaching was not in accordance with the measured porosity of the matrix, and 
they concluded that the chemical stabilization is more important than the physical metal retention in the structure [13].

In the present work, the leaching behavior of zinc ions in cement composites was determined by a modified dynamic leaching test. The concentration of zinc in solutions after leaching is determined by EDXRF device. The mechanical stability of immobilized samples was tested by measuring compressive and flexural strength. Identification of forming hydrated products was carried out using Fourier transformation infrared technique.

\section{MATERIALS AND METHODS}

\subsection{Materials}

For all samples investigated, an ordinary Portland cement (CEM I 42.5R) was used. CEM I was obtained from CEMEX Croatia cement plant (Kaštel Sućurac, Croatia). This cement is characterized by very high early and final strength, a short period of setting time, optimum workability and considerable development of heat of hydration.

Waste zeolite was natural zeolite tuff from the Donje Jesenje deposit, Croatia, saturated by solution containing 9.0 $\mathrm{mmol} / \mathrm{dm}^{3} \mathrm{ZnSO}_{4}$. After saturation with $\mathrm{Zn}^{2+}$ - ions, zeolite was dried at $60{ }^{\circ} \mathrm{C}$, ground and sieved through a standard $4900 \mathrm{mesh} / \mathrm{cm}^{2}$ sieve. The cement and natural zeolite chemical compositions were determined by an EDXRF Twin-X device and are shown in Table 1.

Table 1: Chemical composition of Portland cement and natural zeolite tuff

\begin{tabular}{|l|l|l|}
\hline $\begin{array}{l}\text { Chem. composition, } \\
(\%)\end{array}$ & CEM I & $\begin{array}{l}\text { Natural zeolite } \\
\text { tuff }\end{array}$ \\
\hline $\mathrm{SiO}_{2}$ & 22.85 & 64.94 \\
\hline $\mathrm{Al}_{2} \mathrm{O}_{3}$ & 4.81 & 13.66 \\
\hline $\mathrm{Fe}_{2} \mathrm{O}_{3}$ & 2.79 & 2.03 \\
\hline $\mathrm{K}_{2} \mathrm{O}$ & 1.89 & 1.88 \\
\hline $\mathrm{Na}_{2} \mathrm{O}$ & 0.18 & 3.66 \\
\hline $\mathrm{CaO}$ & 65.23 & 2.99 \\
\hline $\mathrm{MgO}$ & 1.61 & 1.10 \\
\hline Loss of ignition & 0.04 & 9.84 \\
\hline
\end{tabular}

Physical and mechanical properties of Portland cement were determined in laboratory tests and are shown in Table 2.

Table 2: Physical and mechanical properties of Portland cement

\begin{tabular}{|l|l|}
\hline Physical property & Value \\
\hline $\begin{array}{l}\text { Specific surface according to } \\
\text { Blaine, } \mathrm{cm}^{2} / \mathrm{g}\end{array}$ & 3300 \\
\hline Standard consistency, \% & 26 \\
\hline Setting time - start, min & 85 \\
\hline Setting time - end, min & 150 \\
\hline Average flexural strength, $\mathrm{MPa}$ & \\
After 2 days & 4.14 \\
After 28 days & 5.61 \\
\hline
\end{tabular}

\begin{tabular}{|l|l|}
\hline Average compressive strength, MPa & \\
After 2 days & 27.42 \\
After 28 days & 51.27 \\
\hline
\end{tabular}

The mud was produced by precipitation of zinc plating plant wastewater with lime and subsequent filtration of the precipitate. The mud was approximately $80 \%$ solids and was composed of a hydroxide gel, hydrated oxides and various metal salts. The mud was dried at $105{ }^{\circ} \mathrm{C}$ to a constant weight, ground and sieved through a standard 4900 $\mathrm{mesh} / \mathrm{cm}^{2}$ sieve. Percentage of the soluble part of the mud was $17.85 \%$ and $\mathrm{pH}$ value was 6.58 . The ground mud was digested using concentrated hydrochloric acid and the concentration of zinc was analyzed using atomic emission spectrometry. The zinc concentration determined was 157.3 $\mathrm{mg} / \mathrm{L}$.

Solidified samples were prepared by mixing different proportions of mud and waste zeolite with CEM I and ultrapure water (Table 3). Control sample was Portland cement without additions, Samples 1-3 were Portland cement samples with 2, 5 and $10 \%$ of mud, and Samples 4-6 were Portland cement samples with addition of 10, 20 and $30 \%$ of the mixture of mud + zeolite. The water/solid (W/S) ratio of prepared cement samples was 0.5 .

Table 3: Different proportions of mud and waste zeolite in Portland cement samples

\begin{tabular}{|l|l|l|l|}
\hline Sample & $\begin{array}{l}\text { CEM I, } \\
\mathrm{g}\end{array}$ & $\begin{array}{l}\text { Natural zeolite tuff, } \\
\mathrm{g}\end{array}$ & $\begin{array}{l}\text { Mud, } \\
\mathrm{g}\end{array}$ \\
\hline Control & 30.0 & 0.0 & 0.0 \\
\hline Sample 1 & 29.4 & 0.0 & 0.6 \\
\hline Sample 2 & 28.5 & 0.0 & 1.5 \\
\hline Sample 3 & 27.0 & 0.0 & 3.0 \\
\hline Sample 4 & 27.0 & 2.4 & 0.6 \\
\hline Sample 5 & 24.0 & 4.8 & 1.2 \\
\hline Sample 6 & 21.0 & 7.2 & 1.8 \\
\hline
\end{tabular}

\subsection{Methods}

\subsubsection{Modified NEN 7345 Leaching Test}

Monolithic cylindrical samples of $34 \mathrm{~mm}$ x $30 \mathrm{~mm}$ were cured in the thermostat for 28 days at a temperature of $20{ }^{\circ} \mathrm{C}$ (isolated contact of samples and water). After solidification, samples were immersed in distilled water (liquid/solid ratio $\mathrm{L} / \mathrm{S}=10: 1)$. Leaching occurred in the sealed glass for defined periods of 18, 72 and 168 hours. After the leaching period, the zinc concentration in eluates was determined by means of an EDXRF device.

\section{Diffusion Model}

Diffusion model uses Fick's law of diffusion, which over the speed of diffusion of zinc assessed the performance of the Solidification/Stabilization $(\mathrm{S} / \mathrm{S})$ process. According to the diffusion model, the actual diffusion coefficients of zinc in stabilizing samples can be calculated using the equation: 


$$
\mathrm{D}_{\mathrm{e}}=\pi \cdot\left[\frac{\left(\frac{a_{n}}{A_{0}}\right)}{(\Delta t)_{n}}\right]^{2} \cdot\left[\frac{V}{S}\right]^{2} \cdot T_{n}
$$

where $D_{e}$ is the effective diffusion coefficient $\left(\mathrm{cm}^{2} / \mathrm{s}\right), a_{n}$ is the zinc loss (mg) during the particular leaching period with index $\mathrm{n}, \mathrm{A}_{0}$ is the initial amount of zinc in the sample $(\mathrm{mg})$, $(\Delta t)_{n}$ is the duration of the leaching period $(s), V$ is the volume of the sample $\left(\mathrm{cm}^{3}\right), \mathrm{S}$ is the surface area of the sample $\left(\mathrm{cm}^{2}\right)$ and $T_{n}$ is the elapsed time in the middle of the leaching period (s).

\section{Assessment of Leaching Index (LI)}

LI is the negative logarithm of the effective diffusion coefficient:

$$
\mathrm{LI}=\left(\frac{1}{\mathrm{~m}}\right) \cdot \sum_{\mathrm{n}=1}^{\mathrm{m}}\left(-\log \left(\mathrm{D}_{\mathrm{e}}\right)\right)_{\mathrm{n}}
$$

where $\mathrm{m}$ is the number of leaching periods.

The value of LI indicates the rate of leaching. The higher the LI value, the lower the speed of leaching of the component with constant availability $U_{\max }$ (this determines the concentration gradient which is the moving force for diffusion):

LI $>$ 12.5: $\quad$ component with low mobility,

$11.0<\mathrm{LI}<12.5$ : component with average mobility,

LI $<11.0$ : component with high mobility.

A LI value of less than 9.5 has no physical significance as the material to be studied has no further internal porosity [14].

\section{Determination of the Controlling Leaching}

\section{Mechanism}

The mechanisms controlling the release of $\mathrm{Zn}$ from the sample were determined using a diffusion model developed by de Groot and van der Sloot [15]. The controlling mechanism is derived from the slope of the curve in equation 3:

$$
\log \left(B_{t}\right)=\frac{1}{2} \cdot \log (t)+\log \left(U_{\max } \cdot d \cdot \sqrt{\frac{D_{e}}{\pi}}\right)
$$

where $B_{t}$ is a cumulative maximum release of the zinc $\left(\mathrm{mg} / \mathrm{m}^{2}\right), \mathrm{U}_{\max }$ is the maximum leachable quantity of zinc $(\mathrm{mg} / \mathrm{kg}), \mathrm{t}$ is contact time $(\mathrm{s}), \mathrm{d}$ is the bulk density of the product $\left(\mathrm{kg} / \mathrm{m}^{3}\right)$ and $\mathrm{D}_{\mathrm{e}}$ is the effective diffusion coefficient $\left(\mathrm{cm}^{2} / \mathrm{s}\right)$. According to this model, if the slope of the linear regression is $0.5, \mathrm{Zn}$ release is slow and diffusion is the controlling mechanism. If the slope is close to 1 , the controlling mechanism is dissolution and if the slope is close to 0 , the mechanism is wash-off.

\subsubsection{Determination of Compressive and Flexural Strength}

Cement mortars were prepared according to standard EN 196-1. The ratio of aggregate and binder (cement + mud + waste zeolite) was constant and it was 3:1. During the preparation of mortars the standardized quartz sand was used, and the water/cement and the water/solid ratio was constant and was 0.5 for all samples. Prepared samples are placed in the mold dimensions $160 \times 40 \times 40 \mathrm{~mm}$ and kept in well-thermostated pool of water at a temperature $\mathrm{T}=20 \pm 1$ ${ }^{\circ} \mathrm{C}$. After a certain period of hydration (1, 2, 7 and 28 days), the samples were conducted to determination of compressive and flexural strength using Toni Technik system of hydraulic presses.

\subsubsection{FTIR Analysis}

Infrared spectra were recorded on a Spectrum One device, Perkin Elmer. The samples were prepared in the form of pellets, and the recording is made in the band from 4000 to $400 \mathrm{~cm}^{-1}$. For the preparation of pellets was used $200 \mathrm{mg}$ of spectrograph pure $\mathrm{KBr}$ (manufactured by Sigma-Aldrich, Germany) were used, mixed with approximately $30 \mathrm{mg}$ of the hydrated samples. After homogenization of the mixture in an agate mortar, the sample was placed into a mold and pressed in a hydraulic press at a pressure of $49.033 \mathrm{MPa}$. Processing of the results was carried out by Spectrum software.

\section{RESULTS AND DISCUSSION}

Based on the diffusion model and zinc concentration in the leaching solutions, the diffusion coefficients, average leaching index and slopes of curves were determined. The slope of curves was used to determine the controlling leaching mechanisms. Results are shown in Table 4 and Figure 1 and 2.

Table 4: Zinc effective diffusion coeficients for cement samples with addition of mud and waste zeolite

\begin{tabular}{|l|l|l|l|}
\hline \multirow{2}{*}{ Effective diffusion coefficient, $\mathrm{D}_{\mathrm{e}}, \mathrm{cm}^{2} / \mathrm{s}$} \\
\hline \multirow{2}{*}{ Sample } & \multicolumn{4}{|l|}{ Time of leaching, hours } \\
\cline { 2 - 4 } & $18 \mathrm{~h}$ & $72 \mathrm{~h}$ & $168 \mathrm{~h}$ \\
\hline Sample 1 & $5.00 \cdot 10^{-9}$ & $8.34 \cdot 10^{-10}$ & $1.00 \cdot 10^{-9}$ \\
\hline Sample 2 & $4.01 \cdot 10^{-10}$ & $2.00 \cdot 10^{-9}$ & $1.00 \cdot 10^{-9}$ \\
\hline Sample 3 & $2.00 \cdot 10^{-9}$ & $4.76 \cdot 10^{-10}$ & $7.82 \cdot 10^{-10}$ \\
\hline Sample 4 & $9.92 \cdot 10^{-10}$ & $1.01 \cdot 10^{-11}$ & $2.00 \cdot 10^{-9}$ \\
\hline Sample 5 & $2.00 \cdot 10^{-9}$ & $1.09 \cdot 10^{-11}$ & $5.37 \cdot 10^{-10}$ \\
\hline Sample 6 & $1.00 \cdot 10^{-9}$ & $2.17 \cdot 10^{-11}$ & $2.65 \cdot 10^{-10}$ \\
\hline
\end{tabular}

According to Nathwani and Phillips, the value of diffusion coefficient of metal in the stabilized samples is between $D_{e}$ $=10^{-5} \mathrm{~cm}^{2} / \mathrm{s}$ for very mobile metal and $D_{e}=10^{-15} \mathrm{~cm}^{2} / \mathrm{s}$ for fully bound metal in the samples [16]. Table 4 shows that values of diffusion coefficient of zinc in samples with different additions of mud (Sample 1-3) ranged from 1.00 . 
$10^{-9}$ to $8.34 \cdot 10^{-10} \mathrm{~cm}^{2} / \mathrm{s}$. It is evident that the zinc in stabilizing samples was very mobile. By adding waste zeolite in cement-mud system, the values of diffusion coefficients were lowered, and zinc ions were less mobile (Sample 4-6). Average values of the leaching index for samples with the addition of mud were lower than criteria limit (LI < 9.5), while the average values of the leaching index for samples with the addition of mixture were above it.

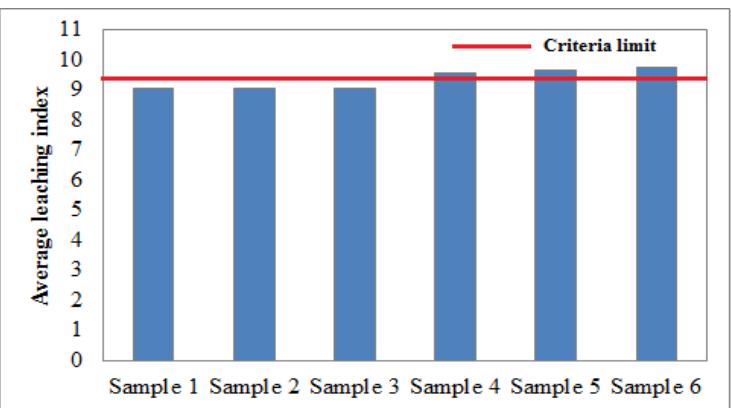

Fig 1: Average leaching index for cement samples with addition of mud and waste zeolite



Fig 2: The controlling leaching mechanism of zinc for cement samples with addition of mud and waste zeolite

Figure 2 shows that the controlling leaching mechanism of zinc in samples with the addition of mud was wash-off (except for Sample 2 where the controlling mechanism was dissolution). In addition of a mixture of mud and zeolite, leaching mechanism was diffusion and wash-off depending on the sample. Figure 3 and 4 show compressive and flexural strength for Portland cement samples with the addition of mud and zeolite.

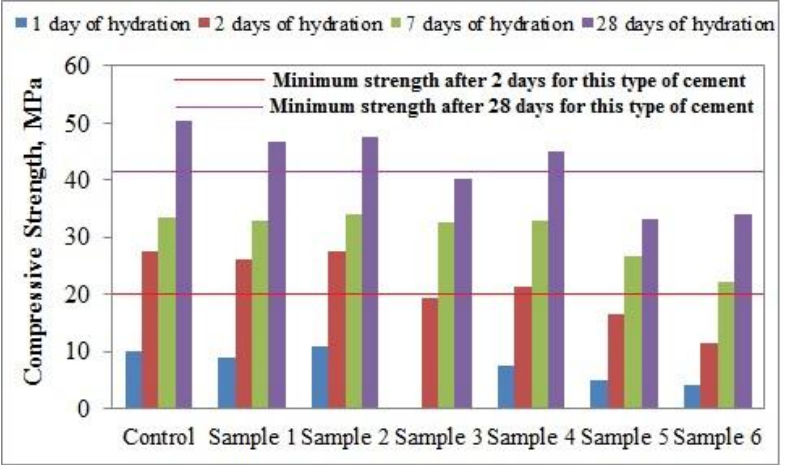

Fig 3: Compressive strength for cement samples with addition of mud and waste zeolite

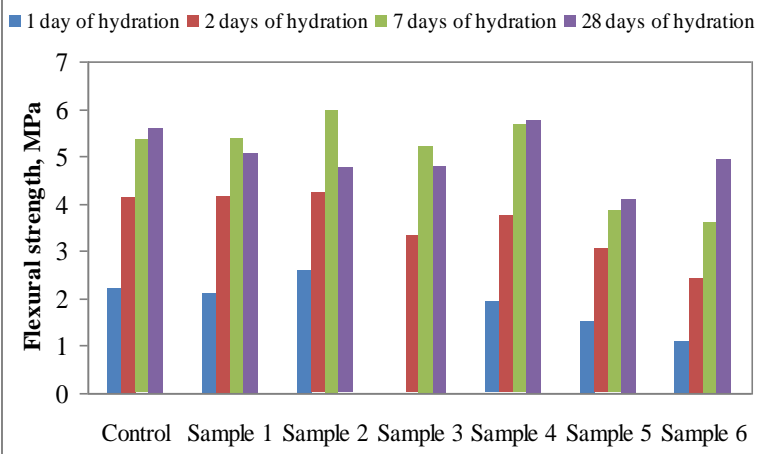

Fig 4: Flexural strength for cement samples with addition of mud and waste zeolite

According to standard EN 197-1, early compressive strength for CEM I should be $\geq 20 \mathrm{MPa}$ (after two days of hydration), and normalized strength (after 28 days of hydration) should be $\geq 42.5 \mathrm{MPa}$. Results show that samples with addition of waste material had lower compressive and flexural strength than the reference sample without the addition. With regard to the standard limit, Samples 1 and 2 meet these conditions. The addition of a mixture of mud and zeolite leads to an even greater reduction in compressive strength. Standard prescribed limit was satisfied only by Sample 4.

Figure 5 and 6 show infrared spectra for Portland cement samples with the addition of mud and zeolite.

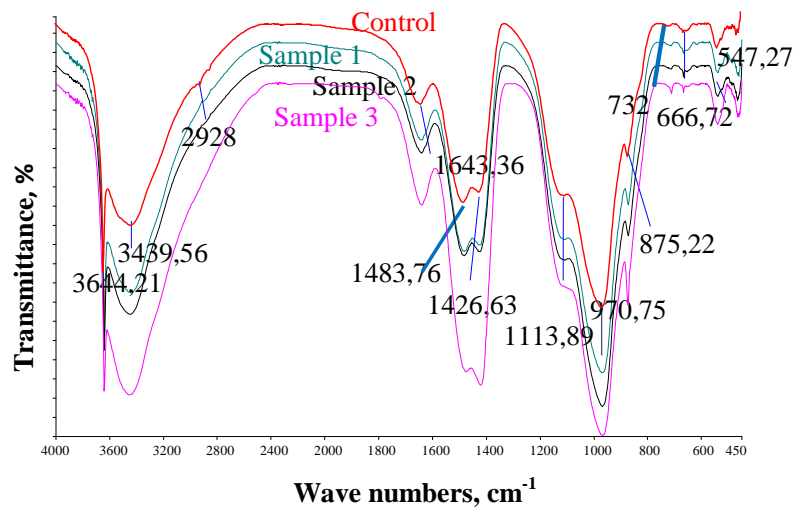

Fig 5: FTIR spectra for cement samples with addition of mud

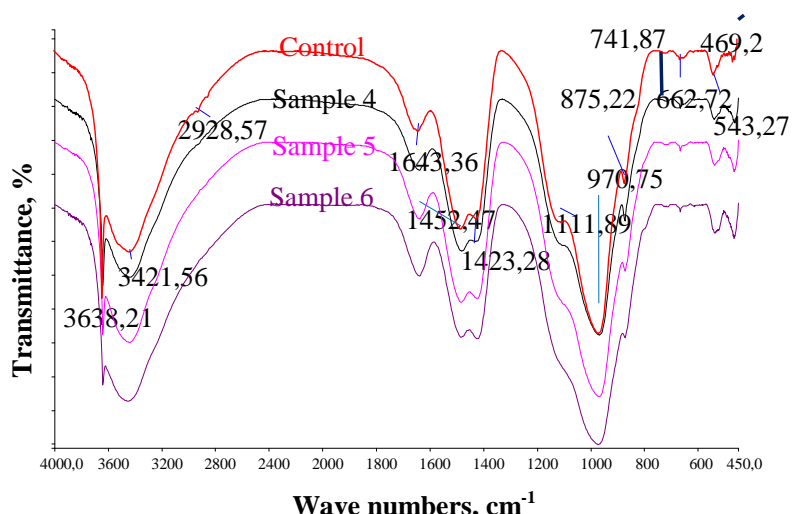

Fig 6: FTIR spectra for cement samples with addition of mixture of mud and waste zeolite 
In the FTIR spectra, characteristic absorption bands were observed in all samples. In the area of wave numbers 3421$3445 \mathrm{~cm}^{-1}$, there is an extended absorption band corresponding bending $\mathrm{H}-\mathrm{O}-\mathrm{H}$ band, while in the area of wave numbers $1638-1652 \mathrm{~cm}^{-1}$ appeared strong absorption band of $\mathrm{H}-\mathrm{O}$ band stretching in the water molecule. The strong absorption bands in the area 3637-3644 $\mathrm{cm}^{-1}$ corresponded to hydroxyl group $\left(\mathrm{OH}^{-}\right)$from Portlandite and metal hydroxides. The addition of mud and waste zeolite reduced the peak intensity and shifted peak to higher values of the wave number. This indicates a negative effect of zinc ions on the hydration of Portland cement. The presence of carbonate phases showed strong absorption bands present in the area 1418-1426 and 1476-1490 $\mathrm{cm}^{-1}$. Band at a wave number of $869 \mathrm{~cm}^{-1}$ was symmetric and asymmetric vibration of Al-O-H bands in the forming ettringite structure of Portland cement samples with additives. The frequency of vibration of Al-O-H band in the Portland cement sample without additives was $875 \mathrm{~cm}^{-1}$. The difference between these frequencies can be evidence of zinc binding in the structure of ettringite. Sulphuric absorption band (vibration $\mathrm{S}-\mathrm{O}$ ) appeared in the wavelength regions corresponding to areas of constitutional water: 1100-1300, 1620-1685 and $3100-3600 \mathrm{~cm}^{-1}$. The basic characteristics of hydrated cement were moving absorption bands of stretching Si-O from the wave numbers of 452,522 and $925 \mathrm{~cm}^{-1}$ for nonhydrated cement to 469,543 and $970 \mathrm{~cm}^{-1}$ for hydrated. The wave number of $970 \mathrm{~cm}^{-1}$ indicated the formation of C-S-H phases. Absorption bands which located in the area of wave numbers $1110-1120 \mathrm{~cm}^{-1}$ corresponding to stretching $\mathrm{Si}-\mathrm{O}$ band from C-S-H phase and represented a proof of polymerization of $\mathrm{SiO}_{4}{ }^{4-}$ chains present in $\mathrm{C}_{3} \mathrm{~S}$ and $\mathrm{C}_{2} \mathrm{~S}$ (silicates "fingerprint"). With addition of mud and waste zeolite, bands shifted towards lower value of wave numbers. Furthermore, the absorption of Si-O-Si band was sensitive to vibrations from $\mathrm{Si}-\mathrm{O}-\mathrm{Si}$ tetrahedra and surrounding structural units. Moulin et al. [17] showed that the zinc tetrahedra incorporated in C-S-H matrix and attached directly to the ends of the silicate chains over $\mathrm{Zn}-\mathrm{O}-\mathrm{Si}$ band, while Komarneni and colleagues [18] have demonstrated that during the binding of the C-S-H structure occurs substitute $\mathrm{Ca}^{2+}$ ions with cations of heavy metals. Binding of zinc in the C-S-H structure, led to changes in the relationships of Si-O-Si tetrahedra in $\mathrm{C}-\mathrm{S}-\mathrm{H}$ structure. More zinc binding led to major shifts of bands.

\section{CONCLUSION}

Modified NEN 7345 leaching test is used to determine the leaching mechanism of zinc from cement composites. Samples with the addition of mud showed high mobility of zinc ions with an average LI value below criteria limit. With the addition of waste zeolite, zinc has become less mobile with greater LI value. According to the diffusion model, controlling mechanism for leaching of zinc was a wash-off (except for the sample with the addition of $5 \%$ of mud). For samples with lower addition of waste zeolite, leaching mechanism was the diffusion, whereas at higher additions, the leaching mechanism was wash-off. Compressive strength of mortars with different additions of mud and zeolite was lower than the compressive strength of a sample without additives. With regard to the standard limit for this type of cement, mud shares are eligible to $5 \%$ and a mixture of mud and zeolite up to $10 \%$.

FTIR spectra indicate the reaction of zinc with the Portland cement hydration products. Zinc lowered intensity of peaks with movement of the peaks toward smaller and larger values of wave numbers. The difference between these frequencies can be evidence of zinc binding in the structure of ettringite and $\mathrm{C}-\mathrm{S}-\mathrm{H}$ phases. More zinc binding led to major shifts of bands.

\section{ACKNOWLEDGEMENTS}

The authors wish to express their gratitude to the Ministry of Science, Education and Sport of the Republic of Croatia, which has been financing the project, a part of which is presented in this report.

\section{REFERENCES}

[1]. Stegemann, J. A., Zhou, Q. 2009: Screening tests for assessing treatability of inorganic industrial wastes by stabilisation/solidification with cement, J. Hazard. Mater. 161: 300-306.Reference 1

[2]. Vijay, R., Sihorwala, T. A. 2003: Identification and leaching characteristics of sludge generated from metal pickling and electroplating industries by toxicity characteristics leaching procedure (TCLP), Environ. Monitor. Assessment 84: 193-202.

[3]. Asavapisit, S., Naksrichum, S., Harnwajanawong, N. 2005: Strength, leachability and microstructure characteristics of cement-based solidified plating sludge, Cem. Concr. Res. 35: 1042-1049.

[4]. Yilmaz, O., Cokca, E., Unlu, K. 2003: Comparison of Two Leaching Tests to Assess the Efectiveness of CementBased Hazardous Waste Solidification/Stabilization, Turkish J. Eng. Env. Sci. 27: 201-212.

[5]. Spence, R. D., Shi, C. 2005: Stabilization and Solidification of Hazardous, Radioactive, and Mixed Wastes, Boca-Raton: CRC Press.

[6]. Crannell, B. S., Taylor Eighmy, T., Krzanowski, J. E., Eusden Jr., J. D., Shaw, E. L., Francis, C. A. 2000: Heavy metal stabilization in municipal solid waste combustion bottom ash using soluble phosphate, Waste Management 20: 135-148.

[7]. Poon, C. S., Peters, C. J., Perry, R., Barnes, P., Barker, A. P. 1985: Mechanisms of metal stabilization by cement based fixation processes, Science of The Total Environment 41: 55-71.

[8]. Poon, C. S., Clark, A. I., Perry, R., Barker, A. P., Barnes, P. 1986: Permeability study on the cement based solidification process for the disposal of hazardous wastes, Cem. Concr. Res. 16: 161-172.

[9]. Paria, S., Yuet, P. K. 2006: Solidification/Stabilization of Organic and Inorganic Contaminants using Portland Cement: A Literature Review, Environmental Reviews 16: 217-255.

[10]. Hills, C. D., Sollars, C. J., Perry, R. 1994: A calorimetric and microstructural study of solidified toxic 
wastes-part 2: a model for poisoning of OPC hydration, Waste Management 14: 601-612.

[11]. Hills, C. D., Pollard, S. J. T. 1997: The influence of interference effects on the mechanical, microstructural and fixation characteristics of cement solidified waste forms, $J$. Hazard. Mater. 52: 171-191.

[12]. Asavapisit, S., Fowler, G., Cheeseman, C. R., Solution chemistry during cement hydration in the presence of metal hydroxide wastes, Cem. Concr. Res. 27: 1249-1260.

[13]. Poon, C. S., Clark, A. I., Peters, C. J., Perry, R. 1985: Mechanisms of metal fixation and leaching by cement based fixation processes, Waste Management and Research 3: 127-142.

[14]. EA NEN 7345: 2004. Leaching Characteristics of Moulded or Monolithic Bulding and Wastes Materials.

[15]. Groot, G. J., Sloot, H.A. 1992: Stabilization and Solidification of Hazardous, Radioactive, and Mixed Wastes, Philadelphia, USA: 149-170.

[16]. Nathwani, J. S., Phillips, C. R. 1980: Leachability of Ra-226 from uranium mill tailings consolidated with naturally occurring materials and/or cement: II. Analysis based on mass transport equation, Water, Air and Soil Pollution 14: 389-402.

[17]. Moulin, I., Stone, W. E. E., Sanz, J., Bottero, J. Y., Mosnier, F., Haehnel, C. 1999: Lead and zinc retention during hydration of tri-calcium silicate: a study by sorption and 29Si nuclear magnetic resource spectroscopy, Langmuir 15: 2829-2835.

[18]. Komarneni, S., Breval, E., Roy, D. M., Roy, R. R. 1988: Reactions of some calcium silicates with metal cations, Cem. Concr. Res. 18: 204-220.

\section{BIOGRAPHIES}

Ph. D. Damir Barbir, University of Split, Faculty of Chemistry and Technology, Department of Inorganic Technology, Teslina 10/V, 21000 Split, Croatia

Tel: +38521329470

Fax: +38521329461

E-mail: dbarbir@ktf-split.hr

Ph. D. Pero Dabić, University of Split, Faculty of Chemistry and Technology, Department of Inorganic Technology, Teslina 10/V, 21000 Split, Croatia

Tel: +38521329470

Fax: +38521329461

E-mail: dabic@ktf-split.hr

B. Sc. Ana Lisica, University of Split, Faculty of Chemistry and Technology, Department of Inorganic Technology, Teslina 10/V, 21000 Split, Croatia

Tel: +38521329470

Fax: +38521329461

E-mail: abubic@ktf-split.hr 